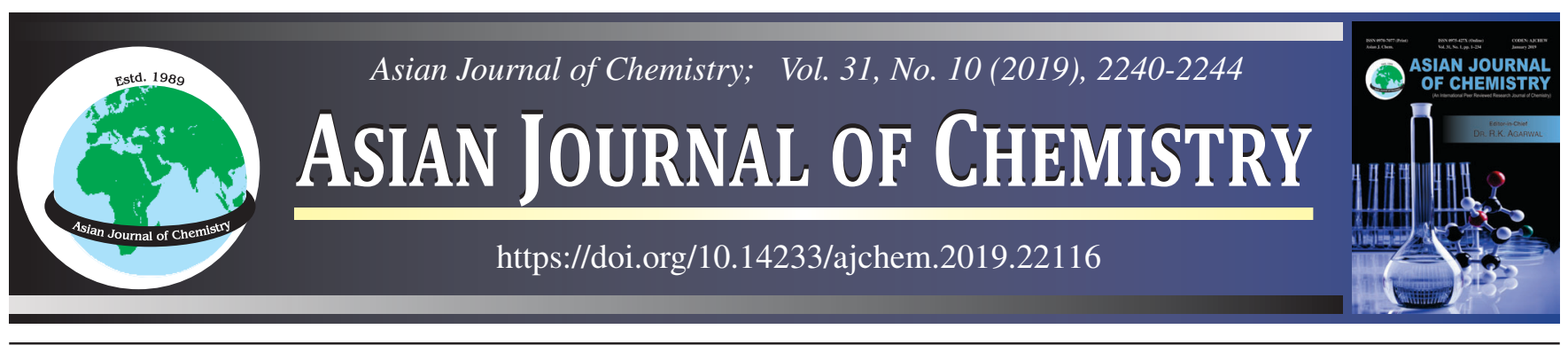

\title{
Simultaneous Removal of Dyes Colour and Cu(II) Metal Ions using Acetone-Formaldehyde-Salicyclic Acid Resin
}

\section{Vihar Patel ${ }^{1}$, Akshit A. Patel ${ }^{1}$, Bharat Dixit $^{2}$ and Ritu Dixit ${ }^{1, *, \bullet}$}

${ }^{1}$ Department of Pharmaceutical Chemistry, Ashok \& Rita Patel Institute of Integrated Study \& Research in Biotechnology and Allied Sciences, (Affiliated to Sardar Patel University), New Vallabh Vidyanagar-388120, India

${ }^{2}$ Department of Chemistry, V. P. \& R. P. T. P. Science College (Affiliated to Sardar Patel University), Vallabh Vidyanagar-388120, India

*Corresponding author: Fax: +91 2692 229189; Tel: +91 2692 231894; E-mail: ritsdixit@yahoo.co.in

Received: 4 April 2019;

Accepted: 18 May 2019;

Published online: 30 August 2019;

AJC-19529

Removal of dyes colour and $\mathrm{Cu}$ (II) metal ion from aqueous solution using acetone-formaldehyde-salicyclic acid (AFSA) resin has been carried out. The results revealed that AFSA resin acts as a cheap substitute to commercial adsorbent like activated carbons. The effects of $\mathrm{pH}$, adsorbent dose, contact time, and initial dye and $\mathrm{Cu}(\mathrm{II})$ metal ion concentration on the adsorption efficiencies were investigated. Isotherm studies were conducted using Langmuir and Freundlich models, and thermodynamic studies were also performed. Adsorption of dyes was found to obey the Langmuir isotherm model and have endothermic process. The maximum adsorption capacities calculated from the Langmuir isotherm were found to be 88.18 and $2.9 \mathrm{mg} / \mathrm{g}$ for methyl orange dyes.

Keywords: Methyl orange dye, Adsorbent, Acetone-formaldehyde-salicyclic acid resin.

L

\section{INTRODUCTION}

Industries have always been and continuous to be the prime cause of economic development like Asian countries, has witnessed several negative environmental consequences. In the field of colours, the dyes are visible pollutants and presence of very minute concentration of colouring substances in water makes it unsuitable for domestic purpose due to its undesirable appearance. Most industries employ dyes and pigments to impart colour to their products $[1,2]$. Around 10,000 different natural and synthetic dyes are being manufactured and their consumers are mainly textile, paper-pulp industries, metals, alloys and plastics, and are responsible for unsafe environment [1]. The textile industry in India and more particular in Gujarat state is one of the oldest and largest industry of nation. The textile mills require highly pure water in huge amount and create equal volume of polluted (i.e. coloured) wastewater. Such dye effluents of these industries are coloured and toxic when high concentrations merged into ground water or drinkable water source. Most of the dyes used in the textile mills are difficult to remove by effluent treatment plant because they are stable against light and microorganism [3]. The discharge of highly coloured effluents into water source is not only aesthetically displeasing but retards light penetration which cause less COD. Several common methods are used for colour removal [4-9], but they have more demerits. Looking to these the activated carbon is the most commonly used adsorbent, however, due to high cost of activated carbon, the low cost material like fly ash, peach, lignite, bagasse, etc. received attention for decolorization of the coloured water. The area in which the removal of the dye using polymer of low cost has received little attention. Moreover, effluents also reach in metal impurities that have detrimental effect on aquatic animals.

Hence, it was interesting to explore the field of simultaneous removal of dyes colour and metal ions using ketonic polymers from effluent water. In present communication, the results of laboratory scale investigations for the colour removal of azo dye solution containing $\mathrm{Cu}$ (II) metal ions using acetoneformaldehyde-salicylic acid (AFSA) copolymeric resin are reported. The effects of process parameters such as adsorbent dose, contact time, initial dye concentration, $\mathrm{pH}$ and temperature have been studied.

This is an open access journal, and articles are distributed under the terms of the Attribution 4.0 International (CC BY 4.0) License. This license lets others distribute, remix, tweak, and build upon your work, even commercially, as long as they credit the author for the original creation. You must give appropriate credit, provide a link to the license, and indicate if changes were made. 


\section{EXPERIMENTAL}

Synthesis of acetone-formaldehyde (AF) resin: The resin was prepared by slight modification of the reported method [7]. Accordingly, a mixture of acetone (1 mol), paraformaldehyde $(0.66 \mathrm{~mol})$ and $30 \mathrm{~mL}$ of $2 \%$ alcoholic $\mathrm{KOH}$ was heated at $5{ }^{\circ} \mathrm{C}$ with constant stirring for $1 \mathrm{~h}$. The resulting mixture was then cooled at room temperature. The so-called resin obtained was in the form of a colourless thick liquid. It was neutralized by formic acid and dried azeotropically. The yield was $94 \%$.

Synthesis of acetone-formaldehyde-salicylic acid (AFSA) resin: Acetone-formaldehyde (AF) resin and salicylic acid in a molar ratio of 1:1, 1:1.5 and 1:2 were refluxed in aqueous solution of $2 \% \mathrm{KOH}$ of the total weight for $3 \mathrm{~h}$. The aqueous layer was decanted and the resultant resin was washed with a large amount of distilled water to remove unreacted material. The water was removed by vacuum. All three resins obtained were pale yellowish amorphous powder. The yield was 83 to $95 \%$ (Scheme-I).

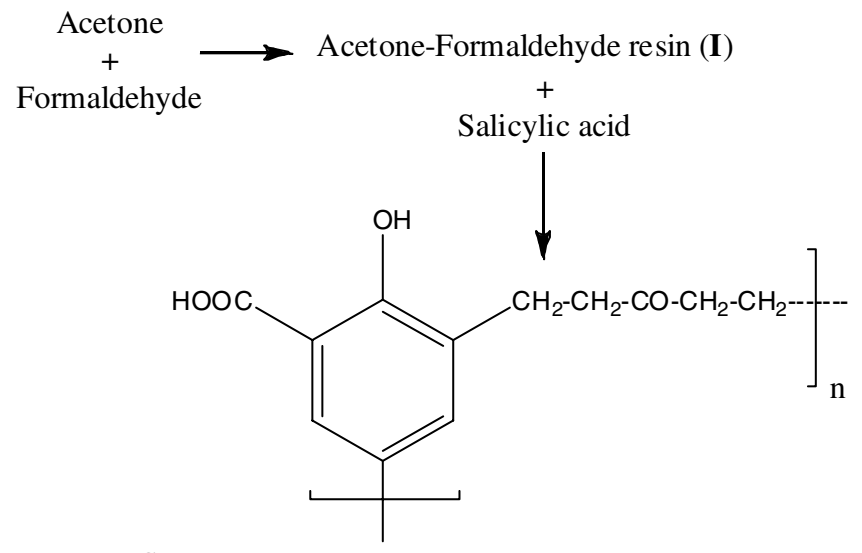

Scheme-I: Proposed synthetic route for AFSA resin

Characterization: Acetone-formaldehyde resin was colourless and soluble in chloroform and tetrahydrofuran. Acetone-formaldehyde-salicylic acid resin is pale yellowish amorphous in colour and soluble in tetrahydrofuran. The viscosity of resin was measured by viscometer (Flow cup method). Storage capacity of resins is stable at least 3 to 4 months. Determination of structure and functional group of both prepared resins were carried out by Fourier transform infrared spectroscopy (FTIR) (Perkin Elmner GX). The molecular weight $\left(\mathrm{M}_{\mathrm{n}}\right)$ determination of prepared resin was carried out by gel permeation chromatography (GPC) (Turbo Matrix 40). Thermal stability was carried out by differential scanning calorimetry (DSC) and thermogravimetric analysis (TGA) (Perkin Elmner Pyris 1).

Batch adsorption experiment: Dye adsorption experiments were conducted in batch mode with $50 \mathrm{~mL}$ stock solution. The variables studies were adsorbent dose, contact time, initial dye concentration, $\mathrm{pH}$ and temperature [10-14]. The solution was stirred by magnetic stirrer for $0.5 \mathrm{~h}$. At the end of experiment, the solution was filtered by vaccum filter system and analyzed by spectrophotometer (Systronics Spectrophotometer 104) at $500 \mathrm{~nm}$. The dye concentration in solution is determined with the absorbance value of solution before and after contact with adsorbent.
Physico-chemical characterization of water effluent: Water effluent was collected from electroplating industry and was analyzed for physical and chemical properties. The obtained data is reported in Table-1.

\begin{tabular}{lc}
\multicolumn{2}{c}{ TABLE-1 } \\
\multicolumn{2}{c}{$\begin{array}{c}\text { PHYSICO-CHEMICAL CHARACTERIZATION } \\
\text { OF WATER EFFLUENT }\end{array}$} \\
\hline \multicolumn{1}{c}{ Parameters } & Characteristics \\
\hline Colour & Light green \\
pH & 5.7 \\
Dissolved oxygen (mg/L) & 1.2 \\
BOD (mg/L) & 4.874 \\
COD (mg/L) & 120 \\
Total solids (mg/L) & 2000 \\
Total dissolved solids (mg/L) & 1000 \\
Total suspended solids (mg/L) & 350 \\
Copper (mg/L) & 8.45 \\
\hline
\end{tabular}

Standard curve of copper(II) ions: Standard curve of copper(II) ions was obtained using standard procedure for estimation of copper (Fig. 1). First solution of copper metal with different ranging from 100 to $500 \mathrm{ppm}$ and 5 to $20 \mathrm{ppm}$ was prepared from aqueous and effluent solution and the irrespective optical density was measured using standard spectrophotometer in visible range $[11,12]$.
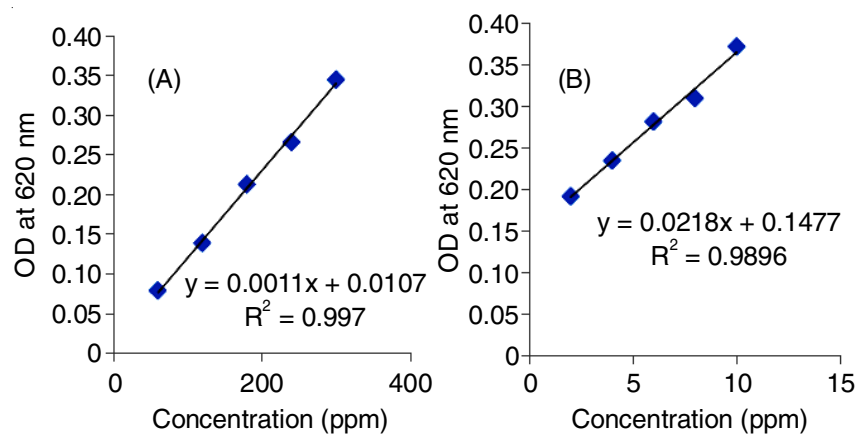

Fig. 1. Standard curve of copper ion in (A) aqueous and (B) effluent solution

\section{RESULTS AND DISCUSSION}

Preliminary observation of acetone-formaldehyde (AF) resin shows that it is soluble in acetone, chloroform, THF and is white sticky gelatinous resin. While acetone-formaldehydesalicylic acid resin is pale yellowish amorphous powder in colour and soluble in THF only.

FITR analysis: For acetone-formaldehyde (AF) resin the broad band appeared from $3600 \mathrm{~cm}^{-1}$ to $3200 \mathrm{~cm}^{-1}$ and sharp peak at $3239 \mathrm{~cm}^{-1}$ attributed to stretching of (-OH) group due to inter and intra-molecular hydrogen bonding of polymeric compound. The strong peak observed at $1484 \mathrm{~cm}^{-1}$ of alkyl $\left(-\mathrm{CH}_{2}\right)$ group, other sharp peak at $1248 \mathrm{~cm}^{-1}$ about $(\mathrm{C}-\mathrm{O})$ group $[15,16]$. For acetone-formaldehyde-salicylic acid (AFSA) resin observed peak at $3428 \mathrm{~cm}^{-1}$ attributed to stretching of $-\mathrm{OH}$ group. Moreover, sharp peak observed at $1703 \mathrm{~cm}^{-1}$ of $(\mathrm{C}=\mathrm{O})$ group and sharp and broad peak observed at $1659 \mathrm{~cm}^{-1}$ and two medium peak observed at 3006 and $3062 \mathrm{~cm}^{-1}$ for aromatic stretching so that, this two medium peak and ketonic group indicate the presence of salicylic acid in AFSA resin. 
Figs. 2 and 3 show the gel permeation chromatography (GPC) of acetone-formaldehyde (AF) and acetone-formaldehydesalicylic acid (AFSA) resin. It allows for the determination of polydispersity index (PDI) as well as the viscosity molecular weight $\left(\mathrm{M}_{\mathrm{v}}\right)$ and based on other data, number average molecular weight $\left(\mathrm{M}_{\mathrm{n}}\right)$, weight average molecular weight $\left(\mathrm{M}_{\mathrm{w}}\right)$ and the size average molecular weight $\left(\mathrm{M}_{\mathrm{z}}\right)$ can be determined. Table- 2 shows the comparison of both resins and description about resin molecular weight and parameters related with polymer.

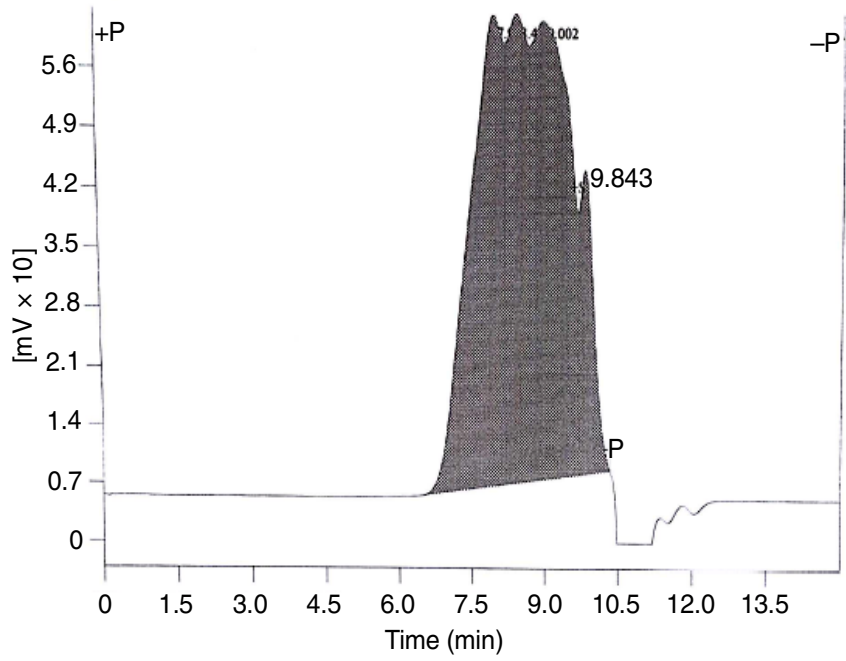

Fig. 2. GPC data of acetone-formaldehyde resin (AF)

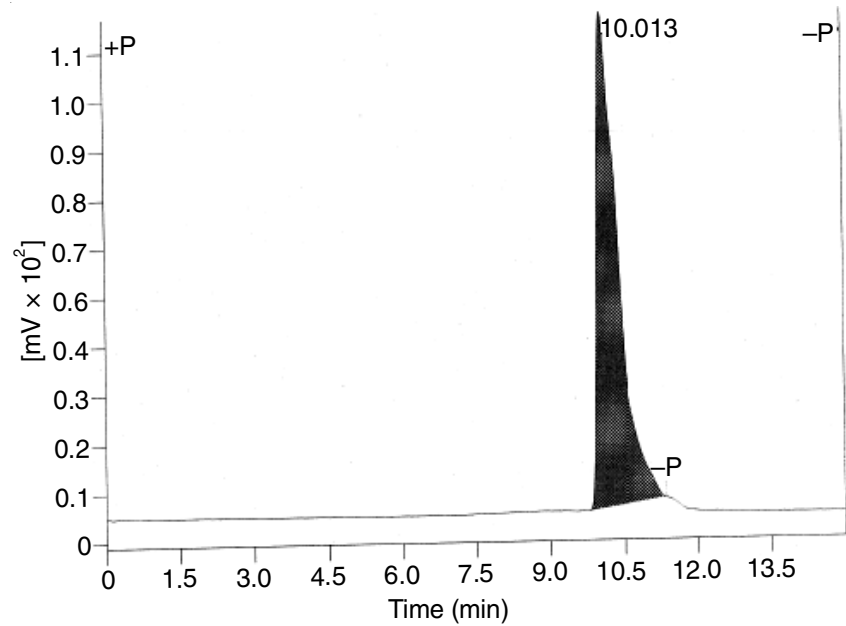

Fig. 3. GPC data of acetone-formaldehyde-salicylic acid resin (AFSA)

Hydrodynamic radius can be calculated; if $\mathrm{n}$ is known and $\mathrm{M}$ as mentioned above:

$$
[\eta] \mathrm{M}=\frac{10 \pi \mathrm{NA}}{3} \times \mathrm{Rn}^{3}
$$

Thus, it is confirmed that AFSA resin is more monodispersed as compared to AF resin.

For homopolymer, (AF and AFSA resin)

$$
\text { Degree of polymerization }(D p)=\frac{M_{n}}{M_{o}}
$$

where $\mathrm{M}_{\mathrm{n}}=$ number average polymer, $\mathrm{M}_{\mathrm{o}}=$ molecular weight of monomer.
TABLE-2

GPC DATA OF AF RESIN AND AFSA RESIN

\begin{tabular}{lcc}
\multicolumn{1}{c}{ Sample } & AF resin & AFSA resin \\
\hline Number average & 1153 & 148 \\
Weight average & 5292 & 174 \\
' $Z$ ' average & 15834 & 194 \\
Polydispersity & 4.589 & 1.178 \\
(n-1) average & 481 & 116 \\
\hline
\end{tabular}

Both samples follow typical trends of average molecular weight for synthetic polymers: $\mathrm{M}_{\mathrm{n}}<\mathrm{M}_{\mathrm{w}}<\mathrm{M}_{\mathrm{z}}<\mathrm{M}_{\mathrm{z}+1}$

Thermal analysis: Figs. 4 and 5 show the differential scanning calorimetry (DSC) of acetone-formaldehyde (AF) resin and acetone-formaldehyde-salicylic acid (AFSA) resin. DSC thermograms of AF and AFSA resin indicate the curing of $\mathrm{AF}$ resin giving a peak in the range of 150 to $210{ }^{\circ} \mathrm{C}$, and AFSA resin system obtained a sharp peak range between 142 ${ }^{\circ} \mathrm{C}$ to $160^{\circ} \mathrm{C}$. From the thermal data of DSC, we can say AFSA resin is well prepared.

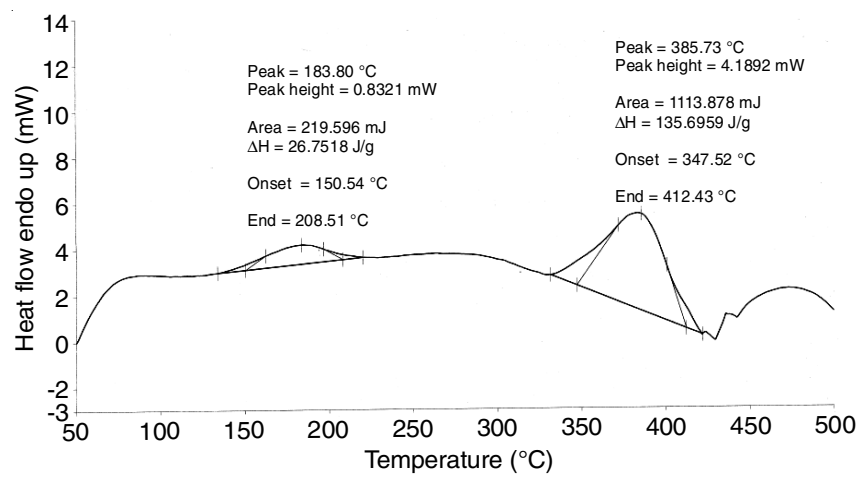

Fig. 4. DSC data of acetone-formaldehyde resin

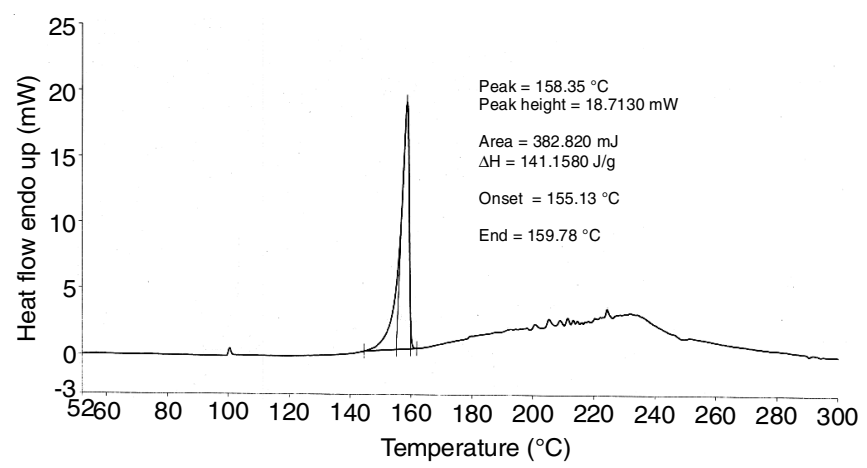

Fig. 5. DSC data of acetone-formaldehyde-salicylic acid resin

Figs. 6 and 7 show the thermogravimetric analysis (TGA) of acetone-formaldehyde (AF) resin and acetone-formaldehyde-salicylic acid (AFSA) resin. The TGA thermograms of both resins AF and AFSA giving information about stability of resin at various temperatures with their percentage weight loss. Both resins degrade in single step. AF resin is stable upto $200{ }^{\circ} \mathrm{C}$ and at the time weight percentage is $95 \%$, and after this temperature decomposition start and weight percentage is decreasing. Degradation is faster between 300 to $425^{\circ} \mathrm{C}$. On other side, AFSA resin decomposition start at $150^{\circ} \mathrm{C}$ and weight percentage is $91 \%$. After this, decomposition starts at $200{ }^{\circ} \mathrm{C}$ and charring started.

Effect of $\mathbf{p H}$ : The results pertaining to the effect of $\mathrm{pH}$ are given in Fig. 8. In $50 \mathrm{~mL}$ solution of constant value of dye 


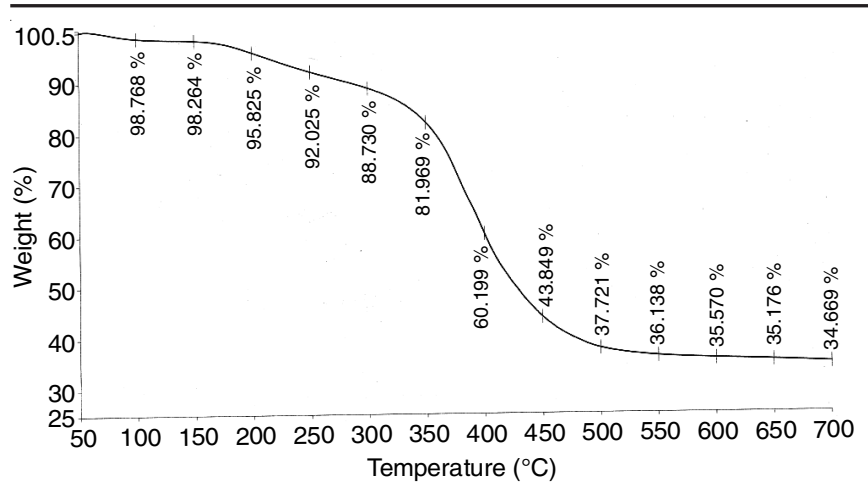

Fig. 6. Thermal curve of acetone formaldehyde resin (AF)

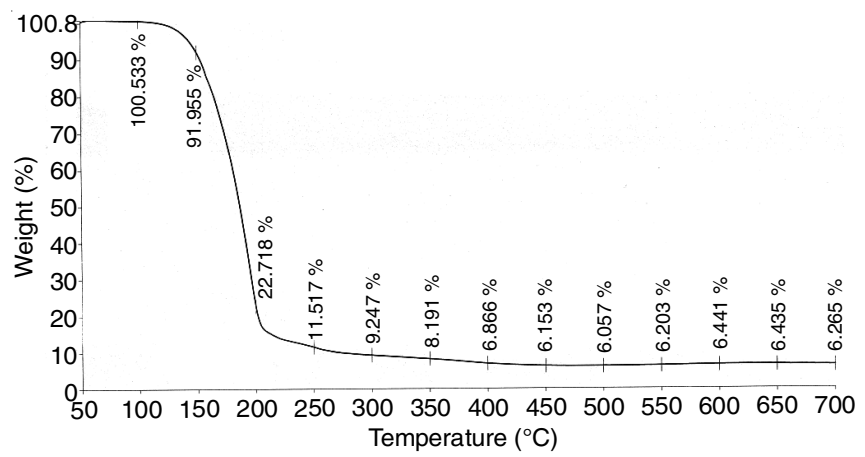

Fig. 7. Thermal curve of acetone-formaldehyde-salicylic acid resin (AFSA)
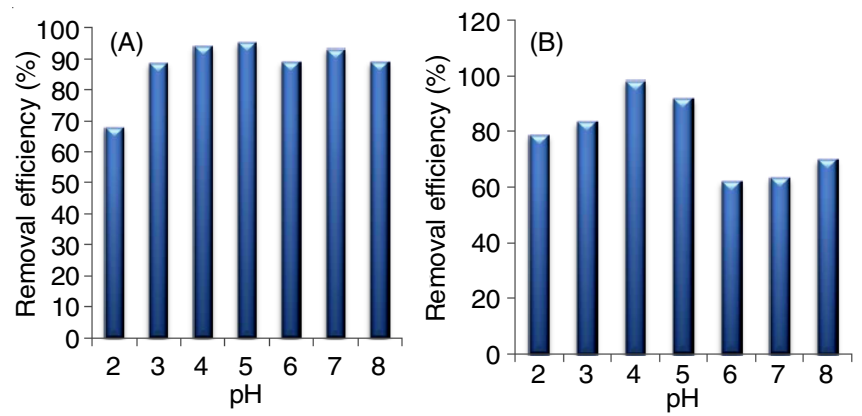

Fig. 8. Removal efficiency (\%) on different $\mathrm{pH}$ for (A) aqueous solution and (B) effluent solution

concentration $(10 \mathrm{mg} / \mathrm{L})$, treated with $1 \mathrm{~g}$ adsorbent dose, the dye removal increases from 90 to $99 \%$ as $\mathrm{pH}$ increases from 2 to 10 . The optimum pH is 6 , where equilibrium is established. With both solutions, the efficiency of copper removal is high at low $\mathrm{pH}$ values and decreases with increase of $\mathrm{pH}$. This is because hydroxyl ions form $\mathrm{Cu}(\mathrm{OH})_{2}$ with copper. Maximum removal of copper was observed at $\mathrm{pH} 5$ and $\mathrm{pH} 4$, and removal efficiency was 95.15 and $98.21 \%$ for aqueous and effluent solution, respectively.

Effect of contact time: The effects of contact time with $1 \mathrm{~g}$ adsorbent dose in $50 \mathrm{~mL}(10 \mathrm{~m} / \mathrm{g})$ dye solution were investigated, the colour removal increases with increase in time. The colour removal reached $75 \%$ within first 20 min. It was observed that as the time increased, the amount of copper that is adsorbed by the sorbent increases, but after $5 \mathrm{~h}$, the solution attains equilibrium. In starting phase, large number of vacant sites may be present, which led to fast adsorption, but afterward, it slows down as the vacant sites maybe exhausted. At equilibrium the colour removal was $96 \%$ (Fig. 9).

Effect of adsorbent dose: Several $50 \mathrm{~mL}$ samples of 10 $\mathrm{mg} / \mathrm{L}$ dye solution were taken and adsorbent with varying dose

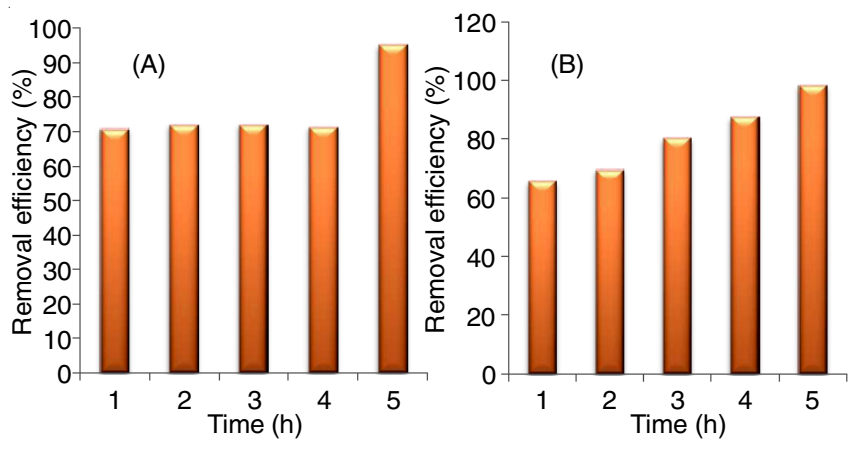

Fig. 9. Removal efficiency (\%) at different time for (A) aqueous solution and (B) effluent solution

from $0.5 \mathrm{~g}$ to $3.0 \mathrm{~g}$ was added. The solution was stirred continuously for $0.5 \mathrm{~h}$. It is found that an increase in the adsorbent dogase does resulted in the increase in removal of dye colours. (Fig. 10).

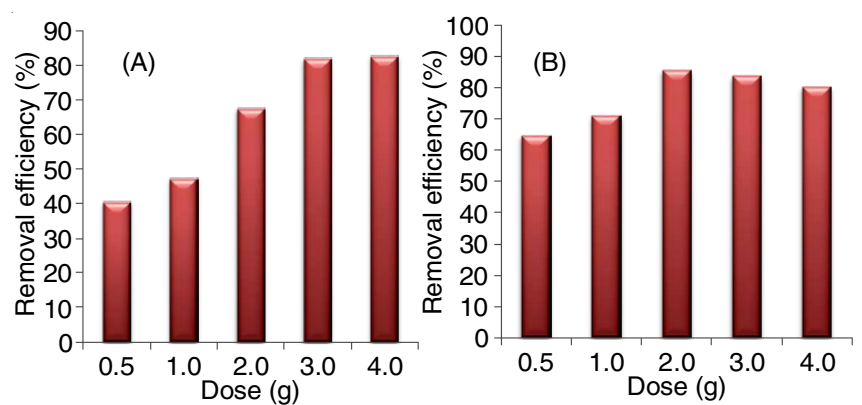

Fig. 10. Removal efficiency (\%) on different dose for (A) aqueous solution and (B) effluent solution

Effect of initial concentration of dye: Constant dose of adsorbent $(1 \mathrm{~g})$ was separately added to $50 \mathrm{~mL}$ sample of different concentration of dye solution $(10 \mathrm{mg} / \mathrm{L}$ to $40 \mathrm{mg} / \mathrm{L})$ at room temperature and the solutions were stirred for $0.5 \mathrm{~h}$ at constant speed. Significant removal of dye was recorded for $10 \mathrm{mg} / \mathrm{L}$ of dye solution, with an increase in initial concentration of dye from $10 \mathrm{mg} / \mathrm{L}$ to $40 \mathrm{mg} / \mathrm{L}$, the dye removal decreases from 95 to $85 \%$ (Fig. 11).
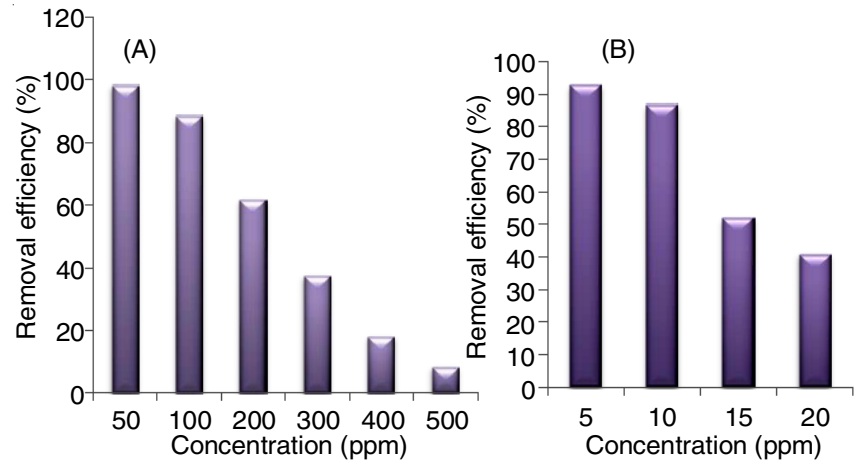

Fig. 11. Removal efficiency (\%) on different concentration for (A) aqueous solution and (B) effluent solution

Effect of temperature: The effect of temperature was also investigated in $50 \mathrm{~mL}$ dye solution of $10 \mathrm{mg} / \mathrm{L}$ concentration treated with $1 \mathrm{~g}$ adsorbent dose. The removal of dye increased from 92 to $100 \%$ with increase in temperature from 20 to 80 ${ }^{\circ} \mathrm{C}$. The optimum temperature in $60^{\circ} \mathrm{C}$, where dye removal is maximum. 
TABLE-3

LANGMUIR ISOTHERM STUDY OF COPPER ON AFSA RESIN

\begin{tabular}{ccccc|ccccc}
\hline \multicolumn{3}{c|}{ Aqueous solution } & \multicolumn{4}{c}{ Effluent solution } \\
\hline $\begin{array}{c}\text { Initial conc. } \\
\left(\mathrm{C}_{\mathrm{i}}\right)\end{array}$ & $\begin{array}{c}\text { Final conc. } \\
\left(\mathrm{C}_{\mathrm{e}}\right)\end{array}$ & $\mathrm{RE}(\%)$ & $\mathrm{Q}_{\mathrm{e}}$ & $\mathrm{C}_{\mathrm{e}} / \mathrm{q}_{\mathrm{e}}$ & $\begin{array}{c}\text { Initial conc. } \\
\left(\mathrm{C}_{\mathrm{i}}\right)\end{array}$ & $\begin{array}{c}\text { Final conc. } \\
\left(\mathrm{C}_{\mathrm{e}}\right)\end{array}$ & $\mathrm{RE}(\%)$ & $\mathrm{Q}_{\mathrm{e}}$ & $\mathrm{C}_{\mathrm{e}} / \mathrm{q}_{\mathrm{e}}$ \\
\hline 300 & 88.18 & 70.06 & 7.06 & 12.4 & 8.45 & 2.9 & 65.68 & 0.018 & 156.7 \\
300 & 84.54 & 71.82 & 7.18 & 11.7 & 8.45 & 2.58 & 69.46 & 0.019 & 131.8 \\
300 & 84.54 & 71.82 & 7.18 & 11.7 & 8.45 & 1.66 & 80.35 & 0.022 & 73.3 \\
300 & 56.36 & 81.21 & 8.12 & 6.93 & 8.45 & 1.06 & 87.45 & 0.024 & 43.03 \\
300 & 14.54 & 95.15 & 9.51 & 1.52 & 8.45 & 0.15 & 98.21 & 0.027 & 5.45 \\
\hline
\end{tabular}

Adsorption isotherm analysis of copper using sorbent: Isotherm analysis gives significant information about the rate of metal uptake and hydrodynamic parameter which helps for successful adsorption of copper metal by the polymer resin. The Langmuir and Freundlich are two useful models which give the information about the equilibrium.

Langmuir isotherm: Fig. 12 shows the results of adsorption isotherm for copper(II) ion. The straight lines plotted indicate the occurrence of ion metal adsorption from the treated samples. This can be proved by looking at the coefficient of determination $\left(\mathrm{R}^{2}\right)$, where $\mathrm{R}^{2}$ is 0.99 and 0.98 for aqueous and effluent solution (Table-3).
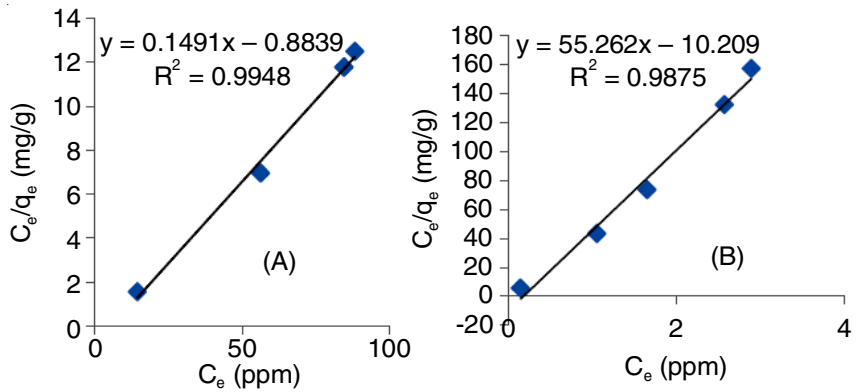

Fig. 12. Langmuir isotherm curve for (A) aqueous and (B) effluent solution

Freundlich isotherm: Fig. 13 shows an adsorption isotherm for copper(II) ions, in which a linear line of aqueous solution shows that data fitted on Freundlich model but non-linear of effluent solution shows that data not fitted on Freundlich model, where $R^{2}$ value is 0.95 and 0.82 , respectively.
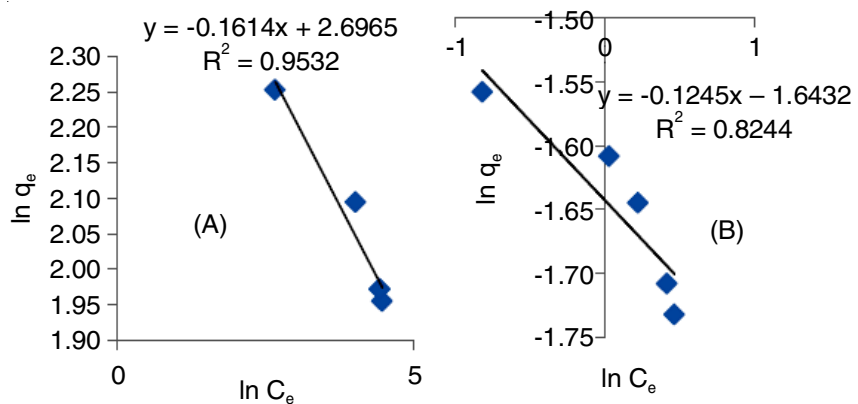

Fig. 13. Freundlich Isotherm curve for (A) aqueous and (B) effluent solution

\section{Conclusion}

Acetone-formaldehyde-salicylic acid (AFSA) resin was found effective in removing methyl orange dye as well as $\mathrm{Cu}$ (II) ions from aqueous solution. It has been identified as an efficient material which is capable of removing copper from both aqueous and effluent solution to the extent of 95.15 and 98.21
$\%$ at the solution $\mathrm{pH}$ of 5 and 4 , respectively. The minimum resin dose required for removal was found to be $3 \mathrm{~g}$ at $\mathrm{pH} 4$ and 5 . The contact time required for batch process was $5 \mathrm{~h}$ at 130 rpm. In adsorption study, Langmuir and Freundlich adsorption models were used to represent the experimental data fitted very well in aqueous solution but Langmuir model fit better than Freundlich model in effluent solution. It can be used as a cheap substitute of commercial adsorbent for removing of dye from textile wastewater.

\section{ACKNOWLEDGEMENTS}

The authors are gratefully acknowledged to Gujarat Council on Science \& Technology, GUJCOST/MRP/2015-16/2595, Gandhinagar, Gujarat, India for the financial support of this research work.

\section{CONFLICT OF INTEREST}

The authors declare that there is no conflict of interests regarding the publication of this article.

\section{REFERENCES}

1. A.R. Lang, Dyes and Pigments: New Research, Nova Science Publishers, Inc.; UK (2013).

2. M. Yusuf, M. Shabbir and F. Mohammad, Nat. Prod. Bioprospect., 7, 123 (2017). https://doi.org/10.1007/s13659-017-0119-9.

3. M. Joshi, R. Bansal and R. Purwar, Indian J. Fibre Text. Res., 29, 239 (2004).

4. M. Malakootian and A. Fatehizadeh, Iran. J. Environ. Health. Sci. Eng., 7, 267 (2010).

5. C.W. Young, R.B. DuVall and N. Wright, Anal. Chem., 23, 709 (1951); https://doi.org/10.1021/ac60053a007.

6. R.M. Osman and S. Al-Masry, Int. J. Adv. Sci. Technol. Res., 4, (2014).

7. H.S. Patel and B.C. Dixit, High Perform. Polym., 9, 153 (1997); https://doi.org/10.1088/0954-0083/9/2/007.

8. D.K. Rath, S. Lenka and P.I. Nayak, J. Appl. Polym. Sci., 46, 2109 (1992); https://doi.org/10.1002/app.1992.070461206.

9. D.T. Masram and K.P. Kariya, Der Pharma Chemica, 6, 292 (2014).

10. S.D. Alexandratos, A.W. Trochimczuk, E.P. Horwitz and R.C. Gatrone, J. Appl. Polym. Sci., 61, 273 (1996); https://doi.org/10.1002/(SICI)1097-4628(19960711)61:2<273::AIDAPP9>3.0.CO:2-M.

11. K. Singh, D.H. Lataye and K.L. Wasewar, J. Hazard. Toxic Radioact. Waste, 20, 04015024 (2016); https://doi.org/10.1061/(ASCE)HZ.2153-5515.0000309.

12. A.M.E. Sulieman, A. Wahid, M. Yousif and A.M. Mustafa, Fourteenth International Water Technology Conference, IWTC-14 2010, Cairo, Egypt, pp 305-315 (2010).

13. R.S. Lokhande, P.U. Singare and D.S. Pimple, Int. J. Ecol., 1, 1 (2010).

14. S.O. Eze, J.C. Igwe and D. Dipo, Int. J. Biol. Chem. Sci., 7, 852 (2013).

15. H.S. Patel and B.C. Dixit, Int. J. Polym. Mater, 42, 309 (1998); https://doi.org/10.1080/00914039808033878.

16. H.S. Patel and B.C. Dixit, Int. J. Polym. Mater., 40, 29 (1998); https://doi.org/10.1080/00914039808050140. 